\author{
ÉDGAR GARCÍA VALENCIA \\ MANUEL A. HERMANN LEJARAZU \\ UNIVERSIDAD VERACRUZANA/CIESAS-UNIDAD DF
}

\title{
Retórica e imagen en el Códice de Yanhuitlán \\ Una propuesta para la lectura de algunas de sus láminas
}

L

A TRADICIÓN PICTÓRICA MIXTECA que sobrevivió a la Conquista española en el primer cuarto del siglo Xvi puede rastrearse claramente en diversos códices y manuscritos elaborados a lo largo del periodo colonial. La gran mayoría de pictografías pertenecientes a esta época conserva aún los trazos, los colores y la iconografía de todo un sistema de registro que, seguramente, comenzó a gestarse desde el periodo Epiclásico o Posclásico temprano en diversas latitudes de Mesoamérica y, es probable, también en el centro de la Mixteca alta, región que participó como foco de gran influencia cultural. ${ }^{\mathrm{I}}$

I. Para un acercamiento más completo a los códices mixtecos y sus temáticas, lugares de origen y características formales, es importante ver el ya clásico trabajo de John B. Glass, "A Survey of Native Middle American Pictorial Manuscripts", y el catálogo de John B. Glass y Donald Robertson, "A Census of Native Middle American Pictorial Manuscripts", ambos publicados en el Handbook of Middle American Indians, vol. I 4: Guide to Ethnohistorical Sources, part three, Austin, University of Texas Press, 1975, pp. 3-252. Actualmente, Michel Oudijk prepara una versión actualizada del catálogo de códices en Wiki-filología (http://I32.248. Io I.2 I 4/wikfil/index.php/portada). También se pueden consultar las obras recientes de Elizabeth Hill Boone, Stories in Red and Black. Pictorial Histories of the Aztecs and Mixtecs, Austin, University of Texas Press, 2000, y Carmen Aguilera, Códices de México, México, Consejo Nacional de Ciencia y Tecnología, 20o I. Para un análisis específico sobre el sistema de escritura mixteco véase el texto de Mary Elizabeth Smith, Picture Writing from Ancient Southern Mexico. Mixtec Place Signs and Maps, Norman, University of Oklahoma Press, I973. 
Podemos decir, en términos generales, que los códices mixtecos narran la historia de los principales señoríos prehispánicos y sus relaciones genealógicas. Pero esta aseveración es demasiado simple pues en los códices podemos encontrar desde mitos de origen hasta detalladas biografías de gobernantes destacados por sus actividades de índole política, guerrera o ritual. Los manuscritos prehispánicos que sobrevivieron a la Conquista española son los códices Nuttall, Vindobonensis, Colombino, Bodley y Selden. Aunque rigurosamente hablando el Códice Selden fue terminado a mediados del siglo xvi, lo consideramos dentro del grupo precolonial debido a que muestra una gran pervivencia del estilo tradicional indígena sin ninguna influencia pictórica occidental.

A pesar de que en los últimos años ha habido un renovado interés por el estudio de los códices mixtecos prehispánicos y coloniales, no todos los aspectos relacionados con su historia y sus contenidos y elementos iconográficos han sido analizados en su totalidad. Existen aún diversos elementos registrados en estos manuscritos que requieren enfoques y planteamientos modernos para mejorar la comprensión de estas pictografías.

Uno de los aspectos que necesita mayor atención de los especialistas se relaciona con el lenguaje o la expresión corporal transmitida a través de los movimientos con las manos, los dedos o cualquier postura del cuerpo. En efecto, particularmente ricos en este tipo de expresiones son tanto los códices mixtecos como los documentos denominados grupo Borgia, en los cuales hay una gran cantidad de representaciones humanas en las más diversas posiciones. La figura humana está representada en los códices dentro de un amplio rango de actividades, tales como estar sentada, de pie, de rodillas, inclinada, sosteniendo objetos, pero, sobre todo, gesticulando con una o ambas manos. ${ }^{2}$

\section{Manos y dedos en los códices prehispánicos de la Mixteca}

Examinando los códices mixtecos, Nancy P. Troike estudió las posturas del cuerpo humano y las gesticulaciones con una o ambas manos en los manuscritos prehispánicos. ${ }^{3}$ Entre los análisis que ha publicado, la autora lanzó la

2. Sobre este tema se puede consultar también la publicación reciente de Pablo Escalante, Los códices mesoamericanos antes y después de la Conquista. Historia de un lenguaje pictográfico, México, Fondo de Cultura Económica, 20 io.

3. Nancy P. Troike, "The Interpretation of Posture and Gesture in the Mixtec Codices", en 
hipótesis de que las posturas y gesticulaciones de los personajes podrían estar funcionando dentro de un sistema de comunicación que expresa información a través de claves visuales para ayudar al lector a interpretar el dato pictórico. ${ }^{4}$ Troike menciona que este trasfondo era conocido sólo por los lectores mixtecos, pero en la actualidad dicho mensaje se encuentra completamente perdido para los investigadores contemporáneos. Por tal razón, esta autora concentra su estudio en un grupo reducido de códices mixtecos para tratar de interpretar ese sistema codificado.

En sus observaciones sobre los movimientos de las manos enfocados en el Códice Colombino, Troike señala que en este documento únicamente hay tres formas de mostrar las manos: apuntando con el dedo índice, con la palma extendida y sosteniendo objetos.

Tanto el dedo apuntando como la palma extendida se sitúan en cinco ángulos diferentes (fig. I): a) directamente hacia arriba; $b$ ) hacia arriba a 45 grados; c) horizontal o ligeramente abajo; d) hacia abajo a 45 grados, y e) directamente hacia abajo.

Después de analizar estas posiciones en el Códice Colombino, la autora concluye: las figuras que gesticulan o tienen movimientos en una zona horizontal están haciendo una petición o solicitud, mientras que las que muestran gesticulaciones en el rango superior aceptan dicha petición y llevan a cabo los deseos de la otra persona. ${ }^{5}$

Por ejemplo, en la página io-II del Códice Colombino encontramos una reunión entre un personaje llamado ıo Viento y un señor identificado por medio de un antifaz negro cuya escena se centra alrededor de una soga y un hacha (fig. 2). Por la posición que tienen los dedos de la mano, Troike piensa que hay una actitud de petición o solicitud por un lado y de aceptación o aprobación por el otro. Es decir, io Viento con el dedo al frente le pide al hombre del rostro pintado que reciba el hacha y la soga, mientras éste, con el dedo levantado, acepta la petición. ${ }^{6}$ No sabemos exactamente si se trata de un tipo de obsequio que ro Viento le da a su compañero o si son instrumentos de autosacrificio que debe emplear el sacerdote del rostro negro, identificado también como 4 Jaguar. Pero en definitiva creemos que hay cierta relación

Elizabeth Hill Boone (ed.), The Art and Iconography of Late Post-Classic Central Mexico, Washington, D.C., Dumbarton Oaks, Trustees for Harvard University, I982, pp. I75-206.

4. Ibidem, p. I80.

5. Ibidem, pp. I 84-1 89 .

6. Ibidem, pp. 189-190. 
a)
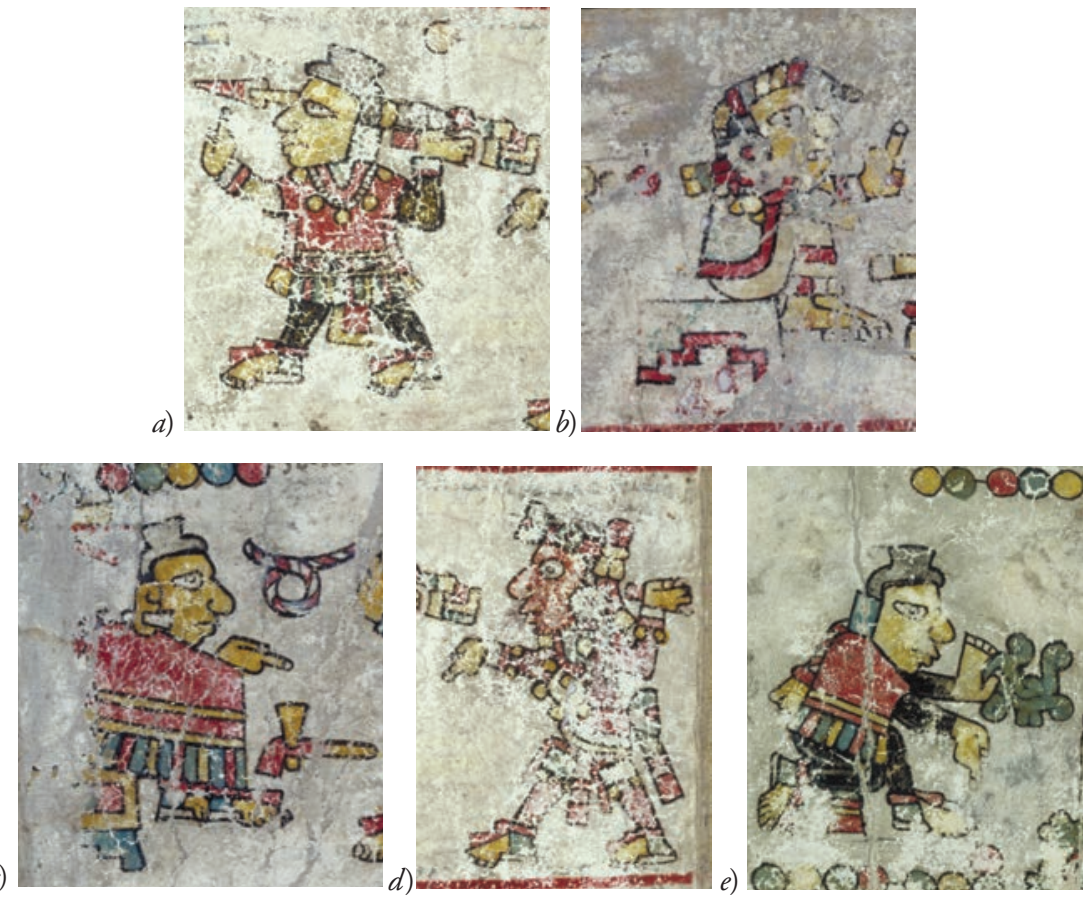

Ia) Dedo apuntando directamente hacia arriba, imagen tomada del Códice Colombino, I-II; b) dedo hacia arriba a 45 grados, ibidem, Io-I; $c$ ) dedo horizontal o ligeramente hacia abajo, ibidem, Io-II; $d$ ) dedo hacia abajo a 45 grados, ibidem, I-II; e) dedo directamente hacia abajo, ibidem, 4-III. Conaculta-INAH-MÉx. "Reproducción autorizada por el Instituto Nacional de Antropología e Historia”.

ritual entre el hacha y la cuerda y el contexto religioso de toda la página que involucra directamente a los personajes relacionados en esta escena.

Otro estudio sobre la gestualidad en los códices mixtecos lo realizaron recientemente Maarten Jansen y Aurora Pérez Jiménez.7 Estos autores proponen que el gesto de apuntar con el dedo podría corresponder con el vocablo mixteco yotasi tnuni, "señalar, mandar", mientras que la mano levantada representa que alguien escuche u obedezca (fig. 3). El dedo levantado puede ser yonaha, "señalar", "aconsejar", "conocer", mientras que la mano extendida parece indicar

7. Maarten Jansen y Aurora Pérez Jiménez, "Paisajes sagrados: códices y arqueología de Nuu Dzaui”, Itinerarios. Revista de Estudios Lingüisticos, Literarios, Históricos y Antropológicos, vol. 8, 2008, pp. 83-II2. 




2. Io Viento (izquierda) hace un ademán de petición y el personaje con antifaz negro (derecha) responde con el ademán de aceptación. Imagen tomada del Códice Colombino, IO-II. Conaculta-INAH-MÉx. "Reproducción autorizada por el Instituto Nacional de Antropología e Historia”.

yosaha, "dar", "repartir", y el acto de tirar tabaco puede componerse con los verbos yocoyo, "esparcir", o yodzacana, "echar arriba". ${ }^{8}$ No obstante, estos autores mencionan que no están proponiendo lecturas fijas para tales gestos, sino solamente exploran correspondencias posibles de los signos con verbos en mixteco. ${ }^{9}$

Por otra parte, en un estudio que realizamos previamente sobre el significado de los asientos de poder en los códices mixtecos, ${ }^{10}$ observamos en el Códice Selden que en la mayoría de las parejas gobernantes del señorío de Jaltepec los personajes comparten prácticamente el mismo ademán de señalar al frente. Tanto los hombres como las mujeres apuntan con el dedo en forma horizontal y en muy pocas ocasiones el dedo de alguno de ellos señala ligeramente hacia arriba o hacia abajo. En este análisis tratamos de establecer una posible relación

\section{Ibidem, p. 89 .}

9. Idem.

Io. Manuel A. Hermann Lejarazu, "Códices y señoríos. Un análisis sobre los símbolos de poder en la Mixteca prehispánica”, tesis de doctorado en Estudios Mesoamericanos, 2 vols., México, Universidad Nacional Autónoma de México-Facultad de Filosofía y Letras, 2005. 




3. Apuntar con el dedo correspondería al vocablo yotasi tnuni, "señalar, mandar"; y la mano levantada representa que alguien escuche u obedezca. Imagen tomada de Ferdinand Anders et al., Origen e historia de los reyes mixtecos. Libro explicativo del llamado Códice Vindobonensis, México/Graz, Fondo de Cultura Económica/Akademische Druck- und Verlagsanstalt, I992, p. 52.

de los ademanes con alguna diferencia de rango entre los linajes de las familias contrayentes, pero no encontramos una asociación consistente que indicara que el dedo apuntando hacia arriba sería sinónimo de una mayor jerarquía en el linaje, a diferencia del que tuviera el dedo apuntando al frente o abajo (fig. 4). A su vez, la misma situación apareció respecto a los asientos, ya que, a pesar de la amplia diversidad de asientos con respaldo, pieles de jaguar, pieles de puma, taburetes sin soportes, entre otros, todos los señores y señoras del Códice Selden emplean asientos indistintamente, sin importar alguna forma o diseńo que marque una jerarquía o una pertenencia a algún linaje en particular. ${ }^{\text {II }}$

Por tanto, podemos señalar que en los códices Colombino, Vindobonensis y Selden el mensaje de las gesticulaciones con manos y dedos parece tener significados diferentes en los tres documentos, que no necesariamente se complementan o ayudan a explicar el lenguaje de las escenas representadas. Ello se debe, indudablemente, a las distintas temáticas o contextos en los cuales se enmarcan las representaciones gestuales, pues no es lo mismo un ademán en 
4. 7 Águila (izquierda) y I I Agua (derecha) muestran ademanes con

el dedo apuntando hacia al frente y hacia arriba a 45 grados. Imagen tomada de Alfonso Caso, Interpretación del Códice Selden, México, Sociedad Mexicana de Antropología, I964, p. I-I.



una escena de matrimonio que en una escena ritual, de guerra o de una simple conversación.

\section{ElCódice de Yanhuitlán}

Pero ¿qué ocurre en los códices mixtecos coloniales?, ¿se mantiene el mismo significado en el uso de las manos? A raíz de estas preguntas nos hemos dedicado a estudiar el Códice de Yanhuitlán, que tiene ejemplos muy interesantes de la pervivencia de la escritura indígena mixteca, no obstante al mismo tiempo muestra ya la introducción de elementos y técnicas pictóricas provenientes del occidente europeo. En efecto, en el Códice de Yanhuitlán se pueden observar varias páginas donde perdura el empleo de elementos heredados de la tradición prehispánica, como son el uso del glifo que marca el año a la manera mixteca, la forma característica de representar topónimos con la inclusión del denominado "tablero de grecas escalonadas" que simboliza el concepto ñun (lugar, pueblo) y el prefijo locativo $a$-, cuyo dibujo de boca o mandíbula dentada, también significa lugar (fig. 5).

Sin embargo, por otro lado también es notable la presencia de estilos y formas recogidos de la tradición europea, como la representación humana en escorzo, los pliegues y dobleces de las telas en las vestimentas de los frailes (fig. 6) y la presencia de iglesias y construcciones religiosas a modo de castillos europeos. Incluso es posible percibir la intervención de varios pintores (tay huisi tacu, en mixteco) que plasmaron la información en folios de papel de algodón con filigranas del tipo El peregrino o La cruz sobre el mundo. 


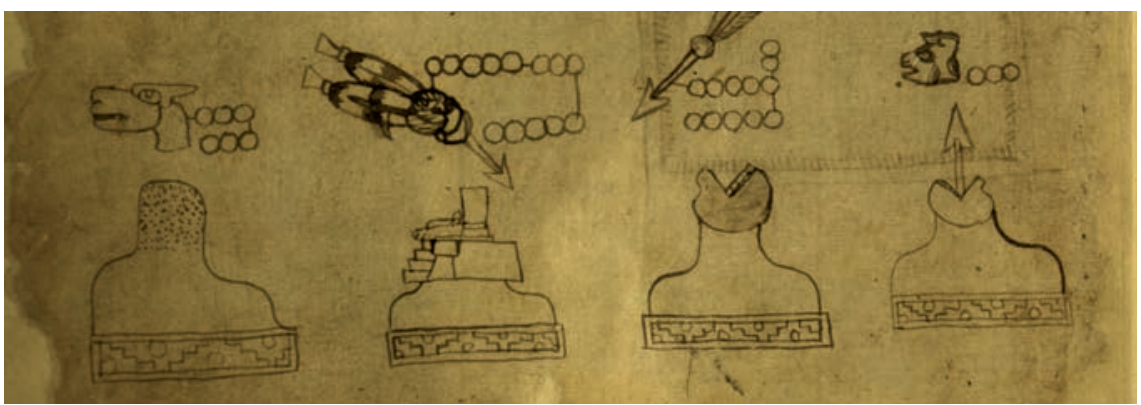

5. Topónimos con el glifo ñuu, pueblo, y el locativo $a$-, lugar. Detalle del Códice de Yanhuitlán, lám. VII. Imagen reproducida con autorización C.B. 86922-4I0IO404. Biblioteca Histórica José María Lafragua de la Benemérita Universidad Autónoma de Puebla, México.

En cuanto a las fechas de elaboración del códice, Wigberto Jiménez Moreno y Salvador Mateos Higuera proponen los años de I545-I550 para su manufactura, tomando como base tanto la datación de las filigranas como los asuntos históricos que contiene el documento. ${ }^{\mathrm{I} 2}$ Los autores reconocen de inmediato que se trata de un manuscrito incompleto, cuyas fojas han sobrevivido de manera fragmentaria y sin orden o consecución lógica, de tal manera que lo ubican como un documento netamente histórico, e incluso lo consideran una sección en la que se iban anotando los hechos sobresalientes relacionados con la vida de los indígenas. ${ }^{\mathrm{I3}}$

A una conclusión semejante llega María Teresa Sepúlveda y Herrera en su estudio sobre este códice, cuando señala que a modo de anales se registraron los hechos importantes para la vida del señorío, la encomienda y la iglesia desde 1520 hasta $1556 .{ }^{14}$ Incluso llega a suponer que la obra fue inspirada por los dominicos, en particular por fray Domingo de Santa María. ${ }^{\text {I5 }}$

María de los Ángeles Romero Frizzi menciona que el Códice de Yanhuitlán contiene la historia de este importante reino de la Mixteca alta, pero agrega que en dicho documento también se pintaron los abusos a que fueron someti-

I 2. Códice de Yanhuitlán, Wigberto Jiménez Moreno y Salvador Mateos Higuera (est. prel.), ed. facs., México, Museo Nacional, I940, pp. 55-56.

I3. Ibidem, p. 56.

I4. Códice de Yanhuitlán, María Teresa Sepúlveda y Herrera (est. prel.), México, Instituto Nacional de Antropología e Historia/Benemérita Universidad Autónoma de Puebla, I 994.

I 5 . Ibidem, p. 96. 
6. Representación de un fraile dominico junto con los señores mixtecos io Mono y 7 Venado. Códice de Yanhuitlán, lám. XIX.

Imagen reproducida con autorización

C.B. 86922-41010404. Biblioteca Histórica

José María Lafragua de la Benemérita Universidad Autónoma de Puebla, México.

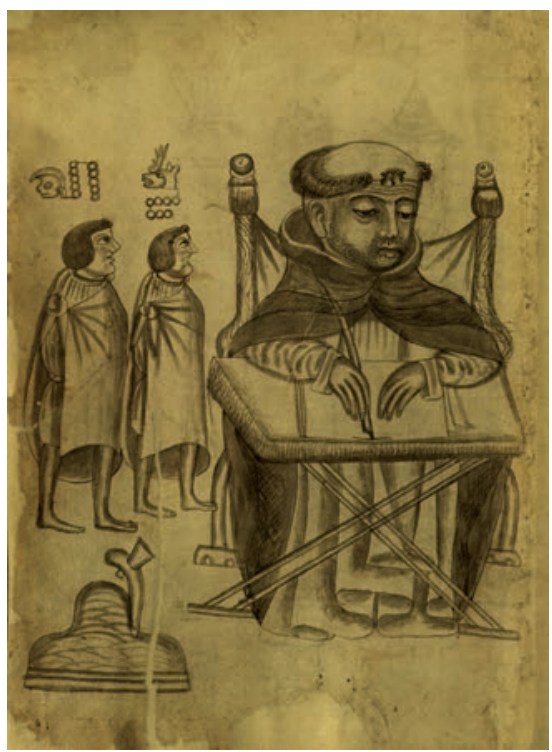

dos los indígenas mixtecos, así como el tributo que estaban obligados a pagar al cacique. ${ }^{16}$

Recientemente, Maarten Jansen y Aurora Pérez Jiménez sugieren que el documento no fue hecho para presentarlo en una corte española, sino que se trató de un libro dinástico semejante a los antiguos códices, que pudo concluirse en 1558 para la entronización de Gabriel de Guzmán en el cacicazgo de Yanhuitlán. ${ }^{17}$

A reserva de nuevos datos que ayuden a esclarecer la naturaleza del códice, pensamos que sí es posible proponer que este documento es producto de algún expediente en el que se registraron las quejas por los abusos de autoridad cometidos por encomenderos, corregidores y frailes dominicos. A lo largo de las fojas se pueden observar las cargas tributarias impuestas a los indígenas, así como los servicios y trabajos que tal vez eran obligados a cumplir para los

I6. María de los Ángeles Romero Frizzi, Teposcolula. Aquellos días del siglo XvI, Oaxaca, Gobierno del Estado de Oaxaca-Dirección General de Culturas Populares/Fundación Harp Helú, 2008, pp. 34-37.

I7. Maarten Jansen y Aurora Pérez Jiménez, La lengua señorial de Nuu Dzaui. Cultura literaria de los antiguos reinos y transformación colonial, México, Gobierno del Estado de Oaxaca-Colegio Superior para la Educación Integral Intercultural de Oaxaca/Universidad de Leiden, 2009, pp. 285-290. 
encomenderos o para los propios frailes, quizá durante la construcción de la iglesia y el convento de Yanhuitlán.

De esta manera, consideramos que el Códice de Yanhuitlán es un documento similar al Códice Osuna, en el que se registran con detenimiento los abusos e injusticias del virrey y los oidores contra los pueblos indígenas de la ciudad de México, Tlatelolco y Tula, entre otros. En el Códice Osuna se acusaba a los oidores de no haber pagado los servicios por la reparación o construcción de sus casas, de llevarse las cargas de hierba y zacate para alimentar a sus caballos y de omitir el pago a los indígenas que participaron en la construcción de la albarrada de San Lázaro y en la edificación de la iglesia mayor o Catedral de México. ${ }^{18}$

No obstante, aún faltan mayores datos para relacionar nuestro documento con determinado tipo de litigio seguido por los indígenas de Yanhuitlán contra alguna autoridad civil o religiosa que pudo haber motivado la realización del mismo. Pero no descartamos la posibilidad de que haya sido el producto de algún proceso contra españoles. El empleo y la dispersión en que actualmente se encuentra el códice obedecen a razones históricas que van de la mano con el desarrollo posterior de los grandes cacicazgos dominados por familias importantes como los Pimentel y Guzmán, quienes aspiraban a obtener el cacicazgo de Tututepec en I653. Precisamente algunos fragmentos del Códice de Yanhuitlán aparecieron en el volumen 272 del ramo de Vínculos en el Archivo General de la Nación, relacionado con el cacicazgo de Tututepec. ${ }^{19}$

Pero en lo que se refiere al tema del presente artículo, fijaremos la atención en la lámina XVI del Códice de Yanhuitlán donde se representa, según Jiménez Moreno y Mateos Higuera, la llegada del obispo de Antequera, Juan López de Zárate, al pueblo de Yanhuitlán hacia I54I..$^{20}$ Es interesante destacar el gran tamaño con que se dibuja un rosario y los ademanes de los personajes principales situados dentro de la escena (fig. 7). Por los detalles en la vestimenta y el sombrero, Jiménez Moreno se inclina a identificar la figura del obispo López de Zárate cuando hace un obsequio al cacique de Yanhuitlán, llamado en el códice 7 Mono, quien se ubica a la izquierda de la lámina y muestra la acti-

I 8. Códice Osuna. Pintura del gobernador, alcaldes y regidores de México, ed. facs., 2 vols., Vicenta Cortés Alonso (est.), Madrid, Ministerio de Educación y Ciencia/Dirección General de Archivos y Bibliotecas, I993.

19. Véase Heinrich Berlin, Fragmentos desconocidos del Códice de Yanhuitlán y otras investigaciones mixtecas, México, Antigua Librería Robredo de José Porrúa e hijos, I 947.

20. Códice de Yanhuitlán, op. cit., I940, p. 64. 
7. El obispo Juan López de Zárate muestra un rosario a 7 Mono. Códice de Yanhuitlán, lám. XVI. Imagen reproducida con autorización

C.B. 86922-41010404. Biblioteca Histórica José María Lafragua de la Benemérita Universidad Autónoma de Puebla, México.

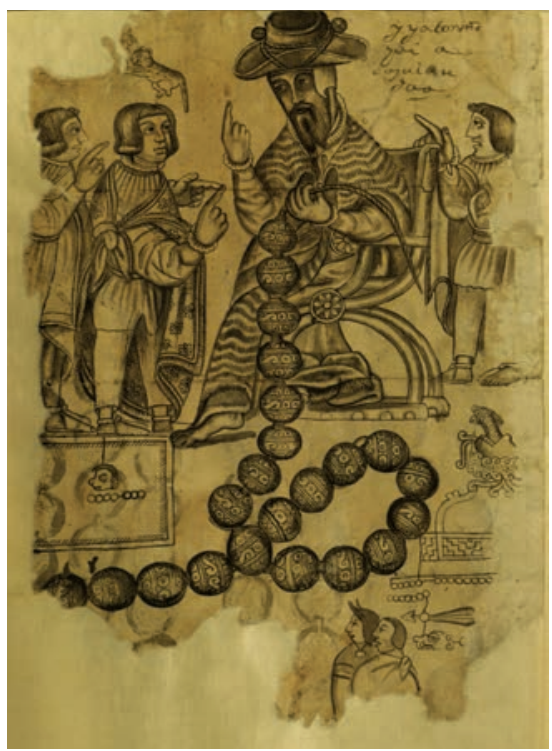

tud de recibir un rosario. Jiménez Moreno relaciona a 7 Mono con el cacique Domingo de Guzmán debido a que observa la figura de un perro en el nombre personal del personaje. ${ }^{2 I}$

Una interpretación alternativa ofrece Sepúlveda y Herrera al mencionar que el hombre sentado en la silla de caderas es fray Tomás de San Juan — conocido también como fray Tomás del Rosario por la gran devoción que tenía a la Virgen María y a su símbolo del rosario. ${ }^{22}$ Por lo mismo, la autora propone que en esta lámina fray Tomás convence a los caciques de Yanhuitlán para instituir la cofradía del rosario que él mismo fundó en México, Puebla y Oaxaca.

Maarten Jansen y Pérez Jiménez también ofrecen una interpretación similar al reiterar que en esta página se está enseñando a los nobles indígenas los misterios o el milagro del rosario, pero, a diferencia de los otros autores, Maarten

2 I. Aunque Maarten Jansen y Aurora Pérez se inclinan a pensar que este personaje en realidad es el joven Gabriel de Guzmán, el cacique de Yanhuitlán, y no su tío don Domingo, pues el glifo que se encuentra arriba de él debe leerse como el nombre mixteco "Jaguar-Antorcha” y no como el emblema de los dominicos domini-canis, "Perros del Señor", "Perros de Dios"; véase Jansen y Pérez Jiménez, La lengua señorial..., op. cit., p. 322.

22. Códice de Yanhuitlán, op. cit., I994, p. I 27. 
Jansen y Pérez Jiménez mencionan que el personaje representado es el encomendero Francisco de las Casas. ${ }^{23}$

Finalmente, Sebastián van Doesburg ha formulado recientemente una interpretación distinta a las anteriores, ${ }^{24}$ basada en la documentación inédita que consultó en el Archivo General de Indias en Sevilla, la cual trata de los juicios de residencia contra Juan Peláez de Berrio, primer alcalde de Oaxaca, en I530.

En estos documentos se narran los abusos de Peláez de Berrio contra españoles e indígenas, pero particularmente importante para nuestro tema es la noticia sobre el obsequio que recibió el alcalde:

Álvaro de Zamora, naguatato, vecino de esta villa [de Antequera], dijo que sabe que al tiempo que salió de esta ciudad de México Juan Peláez de Berrio para venir a esta villa por alcalde mayor, que puede haber más de dos años [i 529], por el mes de junio, estando en el pueblo de Tapascolula y viniendo este testigo con él por su naguatato, vinieron al dicho pueblo los señores de Anguitlan y le dieron un rosario de cuentas de oro y después de dado le pidieron que les diese justicia de García de Escobar [mayordomo de Francisco de las Casas] que había muerto al seńor de Anguitlan y luego el dicho Juan Peláez de Berrio envió a prender al dicho García de Escobar y este testigo vio como recibió Juan Peláez el rosario de oro y no se acuerda cuántas cuentas podían ser. ${ }^{25}$

De esta manera, encontramos aquí otra interpretación plausible de la ya famosa lámina XVI del códice, en la que probablemente se haya pintado al alcalde al momento de recibir un rosario de oro durante su paso por el pueblo de Yanhuitlán en I529. No obstante, aún quedan algunas dudas, pues la vestimenta y el sombrero que porta el personaje principal de la escena parecen aludir a una significación religiosa.

En su interpretación, Maarten Jansen y Pérez Jiménez comentan que el encomendero Francisco de las Casas estaba en un acto evangelizador, pues no necesitaba la ayuda de los dominicos al erigirse como "obispo y papa de su pueblo". ${ }^{26}$ Sin embargo, a nuestro juicio, el encomendero estaría entonces

23. Jansen y Pérez Jiménez, La lengua señorial..., op. cit., pp. 32 I-323.

24. Comunicación personal.

25. Archivo General de Indias (AGI), Justicia, vol. 231, exp. I, cuaderno 4, ff. 577v-578. Agradecemos a Sebastián van Doesburg la referencia que encontró en el AGI, misma que nos proporcionó generosamente.

26. Jansen y Pérez Jiménez, La lengua señorial..., op. cit., p. 323. 
haciendo una usurpación muy grave al hacerse representar como un religioso, pues claramente el sombrero de ala ancha con pequeñas borlas acordonadas en la copa era utilizado únicamente por autoridades eclesiásticas que, de acuerdo con su rango y jerarquía, podían emplearlo en diferentes colores. Por tanto, consideramos que no está del todo resuelta la identificación del personaje central de la lámina XVI del códice, por lo que aún es posible regresar a la propuesta de Jiménez Moreno quien reconoce aquí al obispo Juan López de Zárate. Además, hay un elemento extra: ¿qué significación podríamos dar en esta lámina a los ademanes o gesticulaciones con los dedos tanto del personaje español como de los nobles indígenas de Yanhuitlán?

Si nos atenemos a una tradición prehispánica, de acuerdo con lo analizado en los códices Colombino, Vindobonensis y Selden, el dedo ligeramente inclinado a 45 grados de los nobles indígenas significaría que estos personajes están presentando una solicitud o petición al personaje español que muestra el dedo hacia arriba en señal de aceptación del requerimiento pedido, interpretación que concuerda con lo expuesto por Troike en su trabajo sobre el Colombino.

Si aplicamos la hipótesis de Maarten Jansen y Pérez Jiménez, el gesto de apuntar con el dedo significaría "señalar", "mandar", mientras que el dedo hacia arriba del personaje español representaría los vocablos "señalar", "conocer", "aconsejar". Finalmente, de acuerdo con el Códice Selden, el ademán con el dedo hacia arriba podría indicar cierta preeminencia del personaje español, mientras que el dedo en posición horizontal marcaría igualdad de condiciones o pertenencia a un mismo rango. Pero, como ya hemos señalado, estos significados son muy relativos pues llegar a conclusiones más seguras depende del contexto en que aparecen las acciones de gestualidad en los códices de contenido histórico, genealógico o mítico-religioso. Por ello, los significados encontrados en un códice no necesariamente son útiles para explicar otro.

Pero veamos a continuación otra lectura de los elementos iconográficos del Códice de Yanhuitlán, donde hemos detectado la posible inclusión de elementos de retórica clásica en algunas de sus láminas.

\section{Antecedentes retóricos}

Varios autores han relacionado elementos de la iconografía de códices coloniales con referencias en jeroglíficos y emblemas europeos, géneros deudo- 
res de la causa eficiente de la retórica y la representación. ${ }^{27}$ Por otra parte, la fascinación por imágenes mesoamericanas trascendió a los repertorios alegóricos bien conocidos por poetas y pintores en el Viejo Mundo. Tal es el caso del Imagini delli dei de gl'antichi, de Vicenzo Cartari (I556), ${ }^{28}$ donde pone al alcance de los rétores de ocasión la manera y la explicación para representar virtudes de los dioses del panteón griego y, en su último capítulo, de los dioses indianos de los gentiles. Es seguro que este gusto por las imágenes cruzó el océano Atlántico en ambas direcciones y que más de algún humanista encontró en el lenguaje de los códices un instrumento de difusión con un alto grado de recursos mnemotécnicos. ${ }^{29} \mathrm{El}$ arte de la memoria, en el sentido clásico

27. Véase el trabajo de Pablo Escalante Gonzalbo, "Sobre la posible presencia de los emblemas de Andrea Alciato en el medio de elaboración del Códice florentino" presentado en El Colegio de Michoacán, dentro del III Seminario Internacional de Emblemática Filippo Picinelli (2000), donde asocia algunas ilustraciones del Códice florentino con el Emblematum liber de Andrea Alciato ( $153 \mathrm{I}$ ), así como su compilación titulada El arte cristiano-indígena del siglo XVI novohispano y sus modelos europeos, Cuernavaca, Centro de Investigación y Docencia en Humanidades del Estado de Morelos, 2008. También dedica al tema varios apartados en su último libro, Los códices mesoamericanos antes y después de la Conquista, op. cit. Véase también Juan Benito Artigas, quien descubrió en el cabildo indígena de Metztitlán un pájaro devorando un alacrán, inspirado en un emblema de Alciato. Juan Benito Artigas, "Metztitlán, Hidalgo. Los edificios de la Villa”, Cuadernos de Arquitectura Virreinal, núm. 7, Universidad Nacional Autónoma de México-Facultad de Arquitectura, s.a., pp. I 8-24.

28. Vicenzo Cartari, Imagini delli dei de gl'antichi, Walter Koschatzky (pról.), ed. facs., Graz, Akademische Druck- und Verlagsanstalt, 1963 [primera ed. I647].

29. Cabe destacar el término jeroglifico en el diccionario de las bellas artes de Francisco Martínez, del siglo XviII, pues plantea esta influencia recíproca en los jeroglíficos europeos y americanos ejemplificada con los catecismos testerianos. "Geroglífico: Figura o imagen de que se servían los Egypcios para comunicar sus pensamientos antes de haber hallado el uso del alfabeto. [...] Sábese también que los geroglíficos han estado en uso, no sólo entre los Egypcios, sino también entre los Chinos, Fenicios, Etiopes, Indios, etc. Quando los Mexicanos, después de la Conquista de los Españoles, abrazaron la fe de Jesu-Christo, explicaron por medio de figuras nuestras principales oraciones. Para explicar, v. gr. estas palabras: yo me confieso, pintaban un Indio de rodillas delante de un Religioso. Para indicar a Dios Todopoderoso, dibujaban tres cabezas adornadas de coronas. El rostro resplandeciente de una muger con un niño en brazos, representaba la Virgen María; San Pedro y San Pablo estaban caracterizados baxo la figura de dos cabezas coronadas, al lado de una de ellas había una espada, y al de la otra las llaves.” Véase Francisco Martínez, Prontuario artístico $o$ diccionario manual de las bellas artes, Madrid, Viuda de Escribano, I787, pp. 200-20I. Frances A. Yates indicaba que a muchos de los más antiguos tratados de la memoria los constituyen listas de objetos donde generalmente se comienza con un "paternóster", una nota para tomar en cuenta el estudio de los catecismos jeroglíficos bajo esta visión mnemotécnica. Véase Frances A. Yates, El arte de la memoria, Madrid, Taurus, 1974, p. I30. 
de la retórica, parte de obras fundamentales como De oratore de Cicerón, la anónima Ad herennium y las Institutiones oratoriae de Quintiliano. La memoria artificial servía para poner a disposición del orador una serie de recursos e imágenes necesarios para memorizar un discurso. En la retórica Ad herennium se dice de las imágenes que "éstas eran ciertas formas, notas y simulacros de la cosa que queríamos recordar". Linda Báez aclara: "si deseáramos recordar un caballo, un león o un águila, teníamos que colocar sus imágenes en ciertos lugares. Igualmente las imágenes no sólo guardaban una estrecha similitud con las cosas que representaban, sino que también podían hacer referencia a las palabras".30

Según Frances A. Yates, los dominicos se encontraban en el centro de la tradición del arte de la memoria en el siglo xvi; las obras más importantes de dicha época pertenecen a dos de ellos: Johannes Romberch con el Congestiorum artificiosa memoria ${ }^{3 \mathrm{I}}$ y Cosme Roselio con el Thesaurus artificiosae memoriae. ${ }^{32}$ Sin duda, el texto de Romberch tuvo una influencia notable no sólo en su orden dominica, sino también en un personaje novohispano, el franciscano fray Diego Valadés. En su Rhetorica christiana, ${ }^{33}$ Valadés recrea por su propia mano ${ }^{34}$ varias láminas que aparecen en Romberch. Estas imágenes fueron conocidas por él a través de un texto más difundido y cercano a su tiempo, el Dialogo di M. Lodovico Dolce, nel quale si ragiona del modo di accrescere e conservar la memoria, ${ }^{35}$ principalmente en cuanto a la localización de los sentidos en el cerebro (figs. 8 y 9), así como un alfabeto mnemotécnico. El propio

30. Linda Báez, Mnemosine novohispánica. Retórica e imágenes en el siglo XVI, México, Universidad Nacional Autónoma de México-Instituto de Investigaciones Estéticas, 2005, p. 26.

3I. Johannes Romberch, Congestiorum artificiosa memoria, Venecia, Melchiorum Sessam, I 533.

32. Cosme Roselio, Thesaurus artificiosae memoriae, Venecia, Antonium Paduanium, I 579.

33. Diego Valadés, Retórica cristiana, Tarcisio Herrera Zapién (trad.), ed. facs., México, Fondo de Cultura Económica/Universidad Nacional Autónoma de México, I989 [primera ed. I 579]. El autor viaja a Europa en I 57 I con el cargo de procurador de la provincia franciscana de la Nueva España, por eso publicó allá su obra. Sin embargo, según Ignacio Osorio, el libro se encuentra en muchas bibliotecas conventuales.

34. Ocho de los 27 grabados de la Rhetorica christiana aparecen firmados: F. D. Valades Inventor, F. D. ualades, VAS, y otras bajo F. Didacvs Valades Fecit. Véase Valadés, op. cit.

35. Ludovico Dolce, Dialogo di M. Lodovico Dolce, nel quale si ragiona del modo di accrescere e conservar la memoria, Venecia, Giovanni Battista, Marchio Sessa et Fratelli, I 562. Santiago Arroyo atribuye el uso de las imágenes de Dolce a Romberch porque las láminas pertenecían a la familia Sessa, que había realizado la edición veneciana del libro de Romberch en I 533 y 29 años después el Dialogo de Dolce. Es evidente que se trata de las mismas imágenes. 




8. Localización de los sentidos en el cerebro. Imagen tomada de Dolce, Dialogo di $M$. Lodovico Dolce..., op. cit. (vid. supra n. 35), f. $5 \mathrm{r}$.

Valadés menciona en la Rhetorica, al hablar sobre la memoria artificial: "Por ello, decidí anexar las siguientes figuras. Ludovico Dolce testifica, en su diálogo de la memoria, que quien usó la primera fue Jaime Publicius". ${ }^{6}$ Valadés, misionero en tierras chichimecas, muestra la importancia del arte de la memoria para todo predicador. Uno de los principales objetivos de su libro era formar al orador, sobre todo al orador cristiano. ${ }^{37} \mathrm{Si}$ bien la obra se publica en Italia, su redacción comenzó en México y es un testimonio del tipo y de la forma como se enseñaba retórica en la Nueva España en la mitad del siglo Xvi. ${ }^{38}$

El significado de las posiciones de las manos tiene en los repertorios alegóricos una tradición basada en la retórica clásica. Fuentes iconográficas fueron atribuyendo características a diversas posiciones y atributos que portaban. Si el hombre es la medida de todas las cosas, como señaló Aristóteles, las alegorías no podrían ser otra cosa que figuras humanas y lo que las diferencia entre sí serán

36. Valadés, op. cit., p. 227.

37. Ignacio Osorio, "La enseñanza de la retórica en el siglo Xvi novohispano", en Conquistar el eco, México, Universidad Nacional Autónoma de México, I989, p. 195.

38. Ibidem, p. 197. 




9. Imagen tomada de Valadés, Rhetorica christiana, op. cit. (vid. supra n. 33), p. 222.

los "accidentes" que portaban. ${ }^{39}$ Nos encontramos ante manifestaciones simbólicas que dependen de su contexto para una interpretación adecuada, a manera de una metáfora. Las manifestaciones más claras de las posiciones de la mano fueron elementos claves de la actio y la pronuntiatio, partes de la retórica.

Los tratadistas dominicos que hemos citado destacaron la gesticulación de las manos como parte importante en su arte de la memoria. En ocasiones, esto representa un alfabeto de señas, donde cada posición de la mano estaba asociada a una letra o frase, y así era posible recordar un nombre, cargo o acción. En el Thesaurus artificiosae memoriae hay un capítulo dedicado a la gesticulación de las manos a manera de los alfabetos de sordomudos (fig. Io). $4^{\circ}$ Cabe aquí señalar que estas letras simuladas con las manos podrían ser iniciales o números. En la Rhetorica christiana, Valadés indicaba al lector deseoso de entrenarse en las artes de la memoria artificial que, al momento de construir un locus

39. Ernst H. Gombrich, Imágenes simbólicas. Estudios sobre el arte en el Renacimiento, Madrid, Debate, 200I, vol. 2.

40. Roselio, op. cit., p. 240. 




Io. Alfabeto de manos, tomado de Roselio, Thesaurus artificiosae memoriae, op. cit. (vid. supra n. 32), f. I04v.

mental adecuado para rememorar las cosas, se asegurara de que "todos los sitios estén de tal manera relacionados, que puedan recordar las imágenes ordenadamente, con las letras de una sola palabra o verso. Siguiendo el ejemplo de aquellos que forman las palabras con las iniciales de los representados o de los argumentos". ${ }^{\mathrm{I}}$

En uno de los repertorios simbólicos más influyentes, la Iconología de Cesare Ripa, las manos tenían una disposición fundamental en la construcción de sus alegorías. Básicamente estaban ocupadas con algún atributo, pero en todos los casos la disposición buscaba dar un mensaje muy claro. En la alegoría de la Compunción dice: "debe estar pronta a enmendar la culpa cometida, dando la debida reparación, como lo promete al mostrar la diestra en alto, comprometiéndose además con esto a obrar el bien, conforme a la buena y santa resolución que habrá tomado". ${ }^{2}$ Por otro lado, representa así a la Constancia: "Mujer que aparece con la diestra alzada, llevando con la siniestra una lanza [...]

4I. Valadés, op. cit., p. 245.

42. Cesare Ripa, Iconología, Juan Barja (trad.), Madrid, Akal, 2002, p. 206 [primera ed. I 599]. 


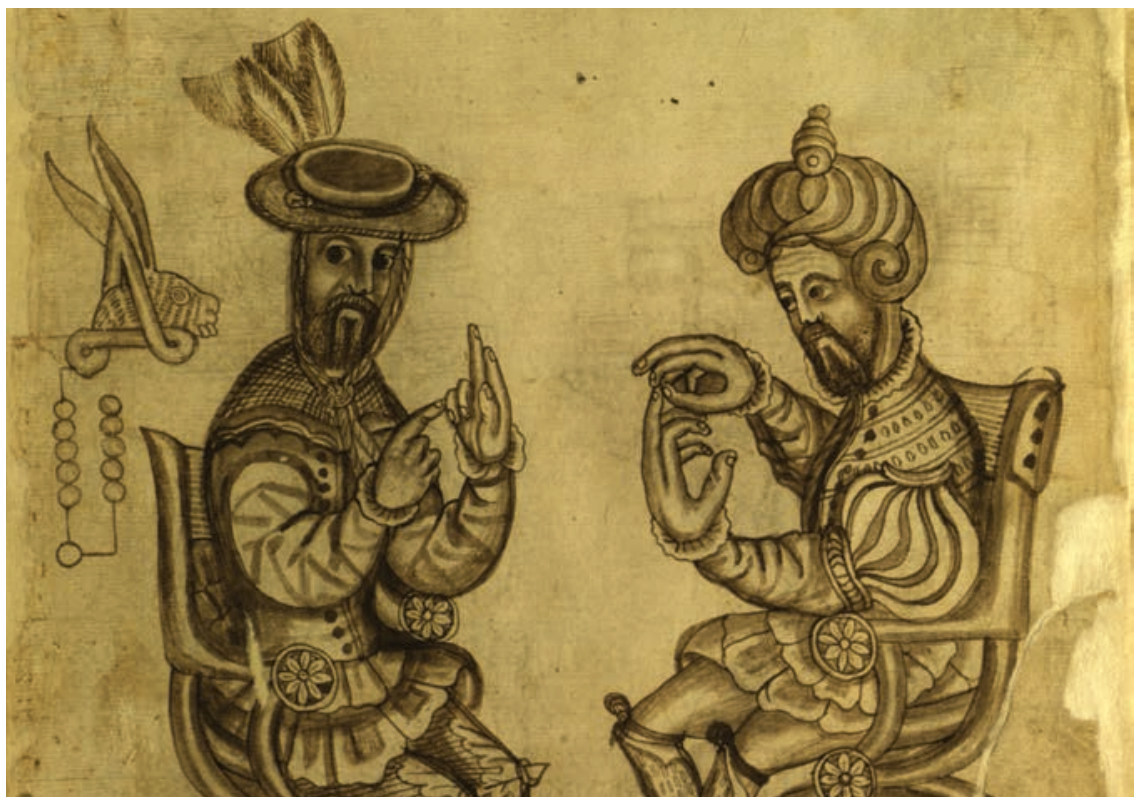

I I. Códice de Yanhuitlán, detalle, lám. VIII. Posibles representaciones de Francisco de las Casas y Gonzalo de las Casas. Imagen reproducida con autorización C.B. 86922-410I0404. Biblioteca Histórica José María Lafragua de la Benemérita Universidad Autónoma de Puebla, México.

La mano que lleva en alto es símbolo de la constancia en todo cuanto se propone". ${ }^{33}$ En los grabados alegóricos, las manos siempre ocuparán una función específica en el mensaje que se transmite, como elementos que respaldan el discurso.

En el Códice de Yanhuitlán tenemos diversos casos en los que las manos, en una desproporción mayor respecto al cuerpo de los personajes, gesticulan y muestran el uso de los dedos de manera singular, como se aprecia particularmente en las páginas VIII y XVI. En la VIII, Jiménez Moreno y Mateos Higuera interpretaron a los dos personajes de esta lámina como encomenderos o corregidores debido a la indumentaria e incluso a su postura. Sin afirmarlo, pensaban que se trataba de Francisco de las Casas y su hijo y sucesor 

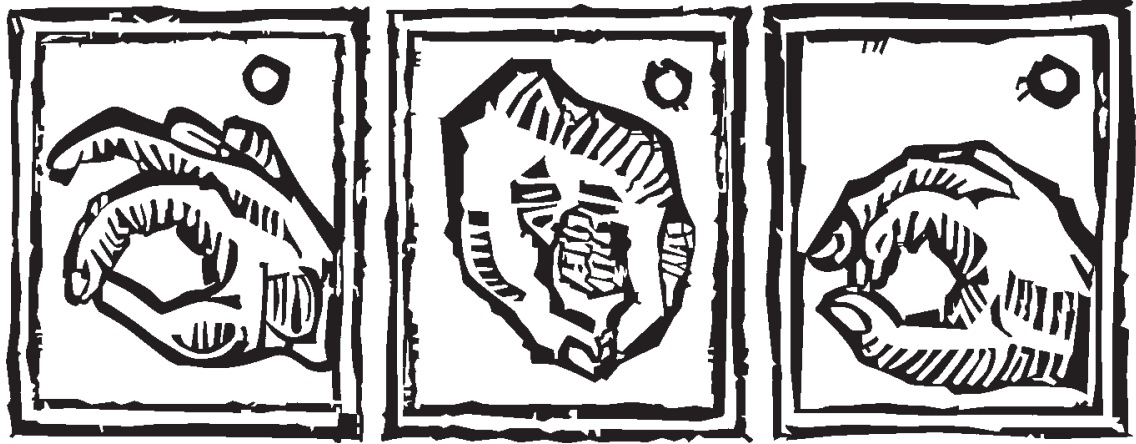

I2. Detalle del alfabeto de manos. Imagen tomada de Roselio, Thesaurus aritificiosae memoriae, op. cit. (vid. supra n. 32), f. I04v.

Gonzalo, o el hermano de éste, Juan. ${ }^{44} \mathrm{La}$ fecha mixteca registrada en el códice fue interpretada como I530 o principios de I53I, cuando debió ponerse en corregimiento la comarca de Yanhuitlán. Esto indicaría también que uno de los personajes pudiera ser el corregidor y el otro el teniente del corregidor (fig. II). ${ }^{45}$ Si siguiéramos la interpretación de las manos como parte de un alfabeto de señas, como el aparecido en Roselio, tendríamos dos iniciales claras en el personaje de la derecha: una mano con la letra $\mathrm{O}$ y otra con la letra G o I (fig. I2).

Como hemos visto, acerca de la lámina XVI del Códice de Yanhuitlán existen diversas interpretaciones para reconocer al personaje central de la escena. Sobre este punto nos hemos inclinado por la propuesta de Jiménez Moreno, quien lo identifica con el obispo Juan López de Zárate. ${ }^{46} \mathrm{Al}$ presunto religioso lo acompañan tres individuos más, representados con un tamaño relativamente menor que el personaje principal, sentado en una silla. Las manos de ellos tienen también un tamaño proporcionalmente mayor que sobresale entre las figuras, lo cual consideramos no una falta de pericia del tay huisi tacu sino una intención de realzar estos elementos en la composición.

En la escena principal, el posible obispo sostiene el rosario con la mano izquierda, mientras que con el dedo índice de su mano derecha apunta hacia

44. Códice de Yanhuitlán, op. cit., I940, p. 60.

45. Ibidem, p. 6I.

46. Ibidem, p. 64. 


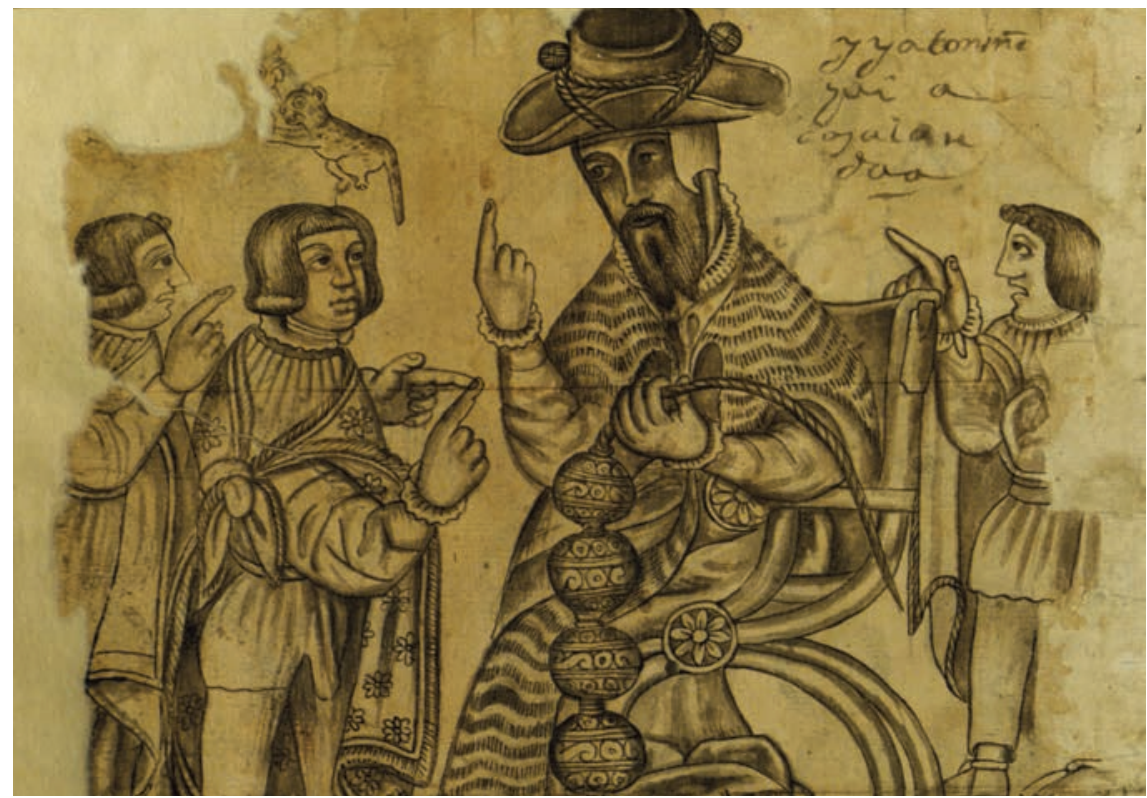

I3. Representación del pronus, Códice de Yanhuitlán, lám. XVI. Imagen reproducida con autorización C.B. 86922-41010404. Biblioteca Histórica José María Lafragua de la Benemérita Universidad Autónoma de Puebla, México.

arriba (fig. I3). Jiménez Moreno y Mateos Higuera identificaron esta escena del siguiente modo:

Parece que trata de explicar algo referente a una unidad, porque todos tienen el índice levantado; quizás con esto el dibujante quiso expresar que el obispo les estaba explicando la existencia de un solo Dios. No parece que se ocupen de asuntos profanos, porque el sacerdote lleva en la mano un rosario de cuentas labradas. ${ }^{47}$

En Quintiliano, el gesto de la mano con el índice extendido lleva el nombre de pronus, y dice: "Y como los tres dedos estén contraídos, entonces ese dedo, el que Cicerón dijo que Craso usaba para explicar, está extendido. Se usa en la denunciación e indicación (de donde tiene su nombre), la mano afir- 


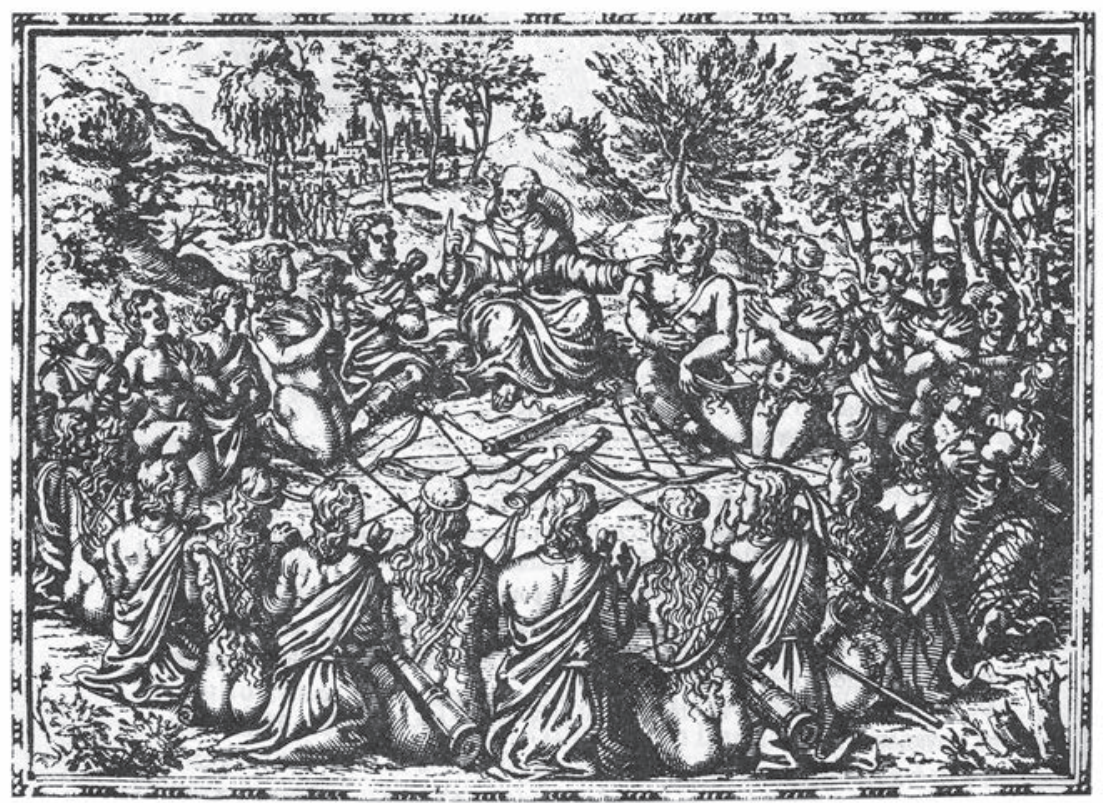

I4. Evangelización de chichimecas. Imagen tomada de Valadés, Rhetorica christiana, op. cit. (vid. supra n. 33), p. 508.

ma si está levantada contrario a si señala hacia la tierra, es como si expresara insistencia". ${ }^{8}$

Uno de los teólogos más importantes del siglo Xvi, Benito Arias Montano, lo utilizó en varios grabados que encargó y en ocasiones dibujó él mismo para sus obras. Este autor, responsable de realizar la edición de la Biblia políglota, usaba ese gesto como quien promueve la concordia y la amistad entre los hombres, dice Linda Báez, teniendo como eje común a Dios. ${ }^{49} \mathrm{El}$ pronus se utilizaba para aludir asuntos celestes y divinos así como la enseñanza de la Trinidad. Por tanto, la primera interpretación de Jiménez y Mateos no está fuera de lugar, aunque pudiera precisarse. No tenemos duda de que el gesto es el pronus, y esto puede indicar un acuerdo o un pacto (fig. I4).

Una última semejanza en la construcción de una imagen es la de la lámina II del Códice de Yanhuitlán (fig. I5) con el grabado i9 que trazó fray Diego

48. Marco Fabio Quintiliano, Institutiones oratorie, apud Báez, op. cit., p. 265.

49. Ibidem, p. 270. 
I5. Reunión en el palacio o aniñe de Yanhuitlán, Códice de Yanhuitlán, lám. II.

Imagen reproducida con autorización

C.B. 86922-4I0I0404. Biblioteca Histórica

José María Lafragua de la Benemérita Universidad Autónoma de Puebla, México.

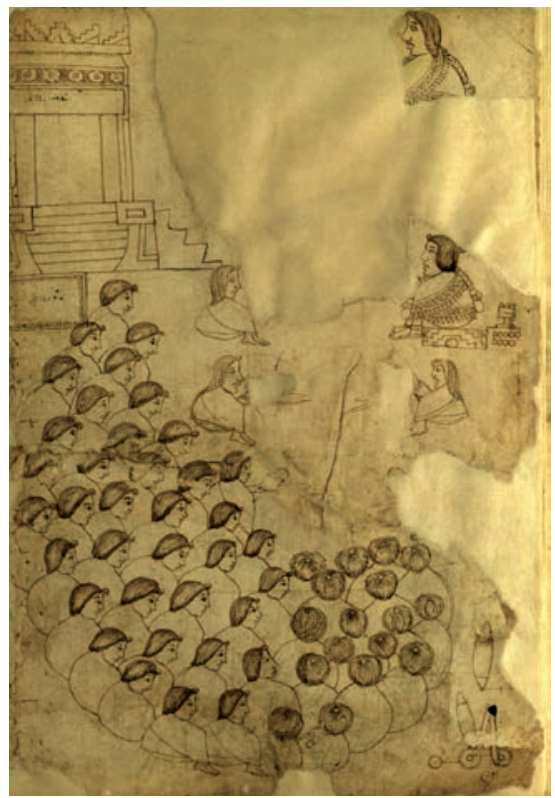

Valadés para representar la evangelización de un grupo de indígenas por medio de imágenes (fig. I6)..$^{\circ}$ La composición creada por Valadés es significativa por la manera en que dispone al grupo de indígenas alrededor de la figura principal que emite el discurso; los indígenas están ubicados en la parte izquierda e inferior del grabado. De igual manera lo resolvió el tay huisi tacu del Códice de Yanhuitlán, aunque en esta ocasión no se trata de una escena de evangelización, sino que la persona principal es el cacique indígena llamado 9 Casa emitiendo un mensaje.

Son sugerentes los elementos de retórica que se observan en el Códice de Yanhuitlán; consideramos que la retórica puede ser un instrumento para aproximarnos con otros ojos al estudio de ciertos elementos de los códices coloniales. Hay que tomar en cuenta la educación que tuvieron los mismos indígenas. Se registra que las clases de retórica llegaron a Oaxaca en 1595 y fueron impartidas por los jesuitas. ${ }^{5 \mathrm{I}}$ Lamentablemente no hay rastros de la presencia de las

50. Valadés, op. cit., p. 2 I I.

5I. Ignacio Osorio, Colegio y profesores jesuitas que enseñaron latín en la Nueva España, México, Universidad Nacional Autónoma de México, 1979, p. 25. 


\section{GARCÍA VALENCIA Y HERMANN LEJARAZU}



I6. Impartición de doctrina, tomada de Valadés, Rhetorica christiana, op. cit. (vid. supra n. 33), p. 477, lám. I9.

obras de los dominicos citados; el único texto que tuvo una gran recepción en las bibliotecas de los conventos fue el de Diego Valadés..$^{52}$ De ser cierta esta influencia, nos daría un probable ámbito de creación del códice a finales del siglo XVI. ¿¿Sus autores mixtecos hicieron suyo un lenguaje retórico? Francisco de la Maza recordaba que si los jeroglíficos se manifestaron como una cultura oculta, proveniente de la sabiduría egipcia, es de notarse que "los mexicanos siempre han gustado de los jeroglíficos, porque los naturales, antes de sujetarse a la dominación de España, escribían notas simbólicas". 53 Una nota sugestiva si pensamos que el lenguaje iconográfico de los indígenas se cultivó casi a la par que los emblemas, por lo cual las imágenes utilizadas, podríamos aventurar, fueron aceptadas con poca dificultad. 54

52. Valadés, op. cit.

53. Justificación citada por Francisco de la Maza, Las piras funerarias en la historia y en el arte de México, México, Universidad Nacional Autónoma de México, I946, p. I7.

54. Linda Báez cita a Diego Valadés: “'la memoria será amplificada lo más fácilmente, cultivándola a la manera de los indios [...]' La expresión 'a la mannera de los indios' tiene su clara razón de ser, puesto que su escritura era pictográfica, por lo que los evangelizadores creyeron ver en ella un paralelo con las pinturas y los jeroglíficos mnemotécnicos de su tiempo", Báez, op. cit., p. 3 I7. 


\section{Conclusiones}

Varias tradiciones parecen confluir en la manufactura del Códice de Yanhuitlán. Por un lado, los elementos de escritura indígena mixteca están claramente representados en glifos de nombres de pueblos y de nombres calendáricos y personales, así como en imágenes de construcciones prehispánicas o de objetos tributados a encomenderos y frailes. Sin embargo, es notorio que en el códice también encontramos elementos que ya pertenecen a la tradición estilística europea y que pueden reflejar la influencia de figuras relacionadas con la evangelización, donde la retórica y el uso de la memoria eran indispensables para los grupos dominicos.

Es indudable que en el Códice de Yanhuitlán concurrieron diferentes artistas o maestros pintores que combinaron sus conocimientos de escritura prehispánica junto con las nuevas técnicas de la pintura y el dibujo traídas de Europa. Son varios los estilos que intervienen en las páginas del códice, cada uno dedicado a plasmar un asunto determinado, por lo que no dudamos en pensar que los autores de las páginas VIII y XVI, por ejemplo, estuvieron más familiarizados con el arte europeo y con los modelos de representación del cuerpo humano que los pintores de páginas dedicadas a topónimos y fechas antiguas. Por tanto, la posible inclusión de figuras retóricas y elementos relacionados con la memoria encaminados a la evangelización bien podría estar presente en estas páginas del códice, cuya polémica en torno a la identificación del personaje principal ha levantado las más diversas hipótesis.

No obstante, no debemos olvidar que en los antiguos códices prehispánicos de la Mixteca las representaciones humanas con gesticulaciones de manos y dedos forman parte de un lenguaje y un sistema de expresiones simbólicas que apenas comenzamos a explorar. La presencia de este lenguaje cifrado a través de los dedos en el Códice de Yanhuitlán bien podría ser solamente una continuidad prehispánica extendida a las representaciones de hombres españoles, por lo que en realidad tal vez podríamos encontrar su significado en los códices elaborados antes de la Conquista y no en la tradición de la retórica europea.

La identificación del personaje principal de la lámina XVI del Códice de Yanhuitlán ha dado motivo a las más diversas interpretaciones. Vimos que algunos autores lo perciben como un poderoso encomendero o, incluso, como el primer alcalde de Oaxaca. Pero, siguiendo a Jiménez Moreno y Mateos Higuera, nosotros lo consideramos una posible imagen del obispo López de Zárate, sobre todo si el gesto del dedo índice hace alusión al pronus. Aunque también 
pudiera existir un significado más cercanamente relacionado con la tradición antigua de los códices prehispánicos, como acabamos de señalar.

Un elemento clave para la interpretación del documento es situar el contexto histórico en el cual fue elaborado; también es necesario definir por qué se pintó y a quiénes estaba dirigido. La época de manufactura del códice aún sigue en discusión, pues mientras los temas, contenidos y algunos estilos del documento bien podrían ubicarse a mediados del siglo XVI, ciertos elementos de influencia europea dentro del contexto de la evangelización podrían indicar que se realizó a finales del mismo siglo.

Debemos, sin duda, realizar más investigaciones para llegar a conclusiones plausibles que expliquen la historia y ciertos aspectos iconográficos de este interesante códice de la antigua tierra de la Mixteca. \$s

* Artículo recibido el I3 de marzo de 20 I i aceptado el 27 de mayo de 20 I I. 